\title{
A three-factor pricing model for cryptocurrencies
}

Article

Accepted Version

Creative Commons: Attribution-Noncommercial-No Derivative Works 4.0

Shen, D., Urquhart, A. and Wang, P. (2020) A three-factor pricing model for cryptocurrencies. Finance Research Letters, 34. 101248. ISSN 1544-6123 doi:

https://doi.org/10.1016/j.frl.2019.07.021 Available at https://centaur.reading.ac.uk/85321/

It is advisable to refer to the publisher's version if you intend to cite from the work. See Guidance on citing.

To link to this article DOI: http://dx.doi.org/10.1016/j.frl.2019.07.021

Publisher: Elsevier

All outputs in CentAUR are protected by Intellectual Property Rights law, including copyright law. Copyright and IPR is retained by the creators or other copyright holders. Terms and conditions for use of this material are defined in the End User Agreement.

\section{www.reading.ac.uk/centaur}

\section{CentAUR}

Central Archive at the University of Reading

Reading's research outputs online 


\title{
A Three-factor Pricing Model for Cryptocurrencies
}

\begin{abstract}
We propose a simple three-factor pricing model, consisting of market, size and reversal factors, to model more than 1700 cryptocurrencies over the sample period from April 2013 to March 2019. We find that small cryptocurrencies have a tendency to obtain higher returns and the reversal returns also increase from larger to smaller cryptocurrencies. Our three-factor pricing model strongly outperforms the cryptocurrency-CAPM model and its performance is robust to different factor constructions.
\end{abstract}

Keywords: Cryptocurrency; Asset pricing; Factors model; Size; Returns reversal 


\section{Introduction}

A series of studies have investigated the predictability of Bitcoin where Urquhart (2016) firstly indicates the inefficiency and predictability of Bitcoin, contradicting the Efficient Market Hypothesis (EMH). This finding has been supported in the literature by Nadarajah and Chu (2017), Tiwari et al (2018) amongst others. Recently, Wei (2018) examines 456 different cryptocurrencies and shows that the less inefficient the cryptocurrency is, the more illiquid the cryptocurrency. Also, studies have shown that external variables through Google Trends data (Urquhart, 2018), the number of tweets (Shen et al, 2019) and Economic Policy Uncertainty (Demir et al., 2018) all have predictive power in the Bitcoin market. In addition, hacks significantly decrease price discovery in the cryptocurrency market (Corbet et al., 2019). Therefore there is clear evidence that cryptocurrencies do not conform the EMH.

However on the basis of rejection of the $\mathrm{EMH}$, what risk factors can help explain cryptocurrency returns? A recent paper by Grobys and Sapkota (2019) shows that the momentum strategy, which has been shown to have strong predictive power in traditional financial markets, implemented on 143 cryptocurrencies generates significantly negative payoffs in the short term, indicating that the digital currency market is free from the persistent momentum effect found across the different financial assets markets. In addition, empirical evidence demonstrates that Altcoins ${ }^{1}$, typically with smaller market capitalization, generate larger profits than Bitcoin does. An analysis released by Masterthecrypto reports that investors will earn 194,730 dollars in a year by holding top ten Altcoins (e.g., Ethereum, Ripple, Litecoin) with an initial 10,000 dollars of capital, but only have 86,000 dollars by investing Bitcoin. ${ }^{2}$ Hence we postulate that the size and reversal effect are common risk factors in cryptocurrency market, which we suggest are a pricing model capturing anomalies in cryptocurrency.

In traditional financial markets, a strand of literature has formed famous factors such from empirical studies, with Banz (1981) showing that small stocks tend to perform better and Fama and French (1993) constructing the "small-minus-big" (SMB) factor. Jegadeesh and Titman (1993) find a tendency for rising assets to continue rising in the future, and Carhart (1997) further introduces a four-factor model involving "winner-minus-loser" (WML). Other stock factors include the "high-minus-low" (HML) value (Fama and French, 1993), "robust-minus-weak" (RMW) profitability, and "conservative-minus-aggressive" (CMA) investment patterns factors (Fama and French, 2015). ${ }^{3}$ We contribute to the literature by proposing that these risk factors can explain cryptocurrency returns. We find that small cryptocurrencies tend to achieve higher returns and the reversal returns also increase from bigger to smaller cryptocurrencies. Our three-factor model has higher explanation than the cryptocurrency CAPM model and the model's performance is insensitive to the factors definition. Therefore we significantly contribute to the literature

\footnotetext{
1 The term "Altcoins" is an umbrella term for any cryptocurrency excluding Bitcoin.

2 For more detailed information, please visit https://masterthecrypto.com/bitcoin-vs-alt-coins-returnscomparison-gains-bitcoin-altcoins/ (accessed: April 15th, 2019).

3 We cannot model these factors given they are based on firm characteristics.
} 
on cryptocurrency pricing.

\section{Data and factors construction}

\subsection{Data}

We collect 1786 different cryptocurrency data ${ }^{4}$ from https://coinmarketcap.com/ covering the period from April $28^{\text {th }} 2013$ to March 31 2019 , with 309 weekly observations in total. ${ }^{5}$ We download the T-Bill as the risk-free asset from the US Department of the Treasury. ${ }^{6}$

\subsection{Predicted momentum returns}

This subsection is to determine the formation and holding period. Following Grobys and Sapkota (2019) who document the significantly negative momentum payoffs in the short term, we further examine the predicted momentum returns in the week-frequency by forming the J-K portfolios based on the prior J weeks' performance with the breakpoints of the top decile (called losers) and bottom decile (called winners), which is ranked in ascending order (consistent with Jegadeesh and Titman 1993). The formation and holding periods are set to 1, 2, 3 and 4 weeks, totally 16 strategies. We form an equally-weighted portfolio consisting of the sell portfolio, the decile of the lowest past return cryptocurrencies, and the buy portfolio which consists of the decile of the highest past return cryptocurrencies. The buy-sell portfolios returns are computed by buying the winners and selling the losers and the returns of the zero-cost portfolio are reported in Table 1. We find pervasive negative returns of buy-sell portfolios and no significant momentum effect except the 4-1 strategy only with significance of $10 \%$. We also observe that 1-1 strategy of buy-sell portfolios has the lowest returns $(-0.220)$ with highest significance (-17.294), and therefore select this specification to construct the factors.

\subsection{Market, size and reversal factors}

We synthesize the value-weight cryptocurrency market returns:

$$
M K T_{t}=\sum_{i=1}^{n} \operatorname{ret}_{i, t} * \frac{\operatorname{Cap}_{i, t}}{\text { TotalCap }_{t}}
$$

where $M K T_{t}$ is the returns of market portfolio in week $t$, ret $t_{i, t}$ denotes the returns for $i_{\text {th }}$ cryptocurrency in week $t, \operatorname{Cap}_{i, t}$ denotes market capitalization of $i_{t h}$ cryptocurrency in week $t$, and TotalCapt $=\sum_{i=1}^{n} \operatorname{Cap}_{i, t}$.

We use six value-weight portfolios formed on market capitalization and prior one-

\footnotetext{
4 There are more than 2000 cryptocurrencies in at the end of March 2019 but we remove some of them whose market capitalization is not provided by coinmarketcap.

5 We use weekly data (consistent with Platanakis et al. 2018, Platanakis and Urquhart 2019) since monthly data would not provide enough observations for a robust study.

${ }^{6}$ https://www.treasury.gov/resource-center/data-chart-center/interest-rates/Pages/default.aspx.
} 
week performance to construct size and reversal factors, which are the intersections of 2 portfolios on size and 3 portfolios on prior returns. The weekly breakpoints of prior returns are the $30^{\text {th }}$ and $70^{\text {th }}$ percentiles while we define cryptocurrencies with top $90 \%$ market cap as the big ones and the bottom 10\% as the small ones (consistent with Fama and French 2012). The six independently formed portfolios are BU, BM, BD, SU, SM and $\mathrm{SD}$, where $\mathrm{B}$ and $\mathrm{S}$ indicate big and small and $\mathrm{U}, \mathrm{M}$, and $\mathrm{D}$ denote up (high prior returns), medium, and down (low prior returns). To ensure that each portfolio has enough cryptocurrencies, we begin sorting after September 2013. Therefore, SMB is the equalweight mean of the three small cryptocurrency portfolios minus the average of the three big portfolios:

$$
\begin{aligned}
S M B & =1 / 3(\text { Small Up }+ \text { Small Medium }+ \text { Small Down }) \\
& -1 / 3(\text { Big Up }+ \text { Big Medium }+ \text { Big Down }) .
\end{aligned}
$$

Since Section 2.2 has confirmed the reversal effect, we construct DMU factor using 1-1 strategy, which is the average return on the two low prior return portfolios minus the average return on the two high prior return portfolios

$$
\begin{aligned}
D M U & =1 / 2(\text { Big Down }+ \text { Small Down }) \\
& -1 / 2(\text { Big Up }+ \text { Small Up }) .
\end{aligned}
$$

As in Fama and French (2012), we also form $5 \times 5$ size-momentum portfolios with breakpoints of $20^{\text {th }}, 40^{\text {th }}, 60^{\text {th }}$ and $80^{\text {th }}$ as LHS assets in regression analysis. ${ }^{7}$ Table 2 reports the average weekly excess returns for $5 \times 5$ value-weight portfolios where we can see the loser portfolios always perform better than the winner and the returns of small groups are larger than those of the big groups on average in most cases. The last column of Table 2 indicates that reversal returns increase from bigger to smaller cryptocurrencies.

\section{Empirical results}

\subsection{Model performance}

Table 3 provides the descriptive statistics for three factors where the SMB and DMU show positive mean returns of 0.063 and 0.160 , with positive skewness and a leptokurtic distribution. The average returns on SMB, DMU are higher than RMRF, indicating that these two factors account for much cross-sectional variations. The RMRF-SMB correlations is 0.015 , RMRF-DMU is 0.024 while SMB-DMU is -0.040 , which imply that multicollinearity does not affect the estimated model loadings.

Inspired by capital assets pricing model in traditional finance, we define the cryptocurrency-CAPM (C-CAPM) as the benchmark where we use excess market returns to explain returns of cryptocurrency portfolios. And the proposed three-factor model is estimated as follows:

\footnotetext{
7 We also construct left-hand variables by using the breakpoints of Fama and French (2012) that roughly correspond to the NYSE quintile, and the results remain unchanged.
} 


$$
r_{i, t}-R f_{t}=\alpha+\beta_{i, 1} R M R F_{t}+\beta_{i, 2} S M B_{t}+\beta_{i, 3} D M U_{t}+\varepsilon_{t}
$$

where $r_{i, t}$ is the weekly returns of $i_{t h}$ portfolios, $R M R f$ is excess return on the market calculated by $R M R F_{t}=M K T_{t}-R f_{t}, S M B_{t}$ and $D M U_{t}$ are size and reversal factors.

Table 4 summarizes the C-CAPM and three-factor regressions to explain weekly excess returns on the portfolios from the $5 \times 5$ sorts on size and reversal ${ }^{8}$, including the average absolute intercept, the average $\mathrm{R}^{2}$, and the average standard error of the intercepts. The C-CAPM, which only incorporates the excess market return as an explanatory variable, performs poorly in our tests. The intercepts are always negative for extreme big portfolios and up portfolios. The C-CAPM has a low $\mathrm{R}^{2}$, i.e., 0.0052 , suggesting very little explanatory power of cryptocurrency returns. Switching to the three-factor model, even though most of the intercepts are negative, the t-statistics are less significant than C-CAPM and the average absolute intercept falls from 0.0356 to 0.0266 . Adding the SMB and DMU returns decreases the average standard error of the intercepts from 0.0149 to 0.0146 . More importantly, the average $\mathrm{R}^{2}$ increases from 0.0052 for the C-CAPM to 0.0695 for the threefactor model. Thus our three-factor model strongly performs better than C-CAPM model.

\subsection{Robustness}

To test the robustness of the three factor model, we sort cryptocurrencies with other breakpoints at the end of each week. Considering that the market capitalization of the top 10 cryptocurrencies is about $80 \%$ of total cap ${ }^{9}$, we define the cryptocurrencies with top $10 \%$ capitalization as the large ones and the bottom $90 \%$ as the small. The breakpoints of prior returns are also the $30^{\text {th }}$ and $70^{\text {th }}$ percentiles. The independent $2 \times 3$ sorts generate six portfolios, namely, BU, BM, BD, SU, SM and SD. The weekly SMB and DMU construction is consistent with Section 3.1. The three-factor regressions to explain weekly excess returns of 25 portfolios are reported in Table 5 where three-factor model shrinks the average absolute intercept from 0.0356 to 0.0288 , the average standard error of 0.0138 is lower than the C-CAPM regressions. Surprisingly, the average $\mathrm{R}^{2}$ increase from 0.0052 to 0.1569 , which improves the precision substantially.

Compared to traditional financial assets, cryptocurrencies are more volatile and the full sample results do not give the whole picture. In that sense, we conduct a rolling regression with the window length of one year (52 weeks) and the step of 1 week. Figure 1 illustrates the rolling results of the $\mathrm{R}^{2}$ and absolute intercepts. Compared with the static results reported in Panel B of Table 4, we find that the three-factor $\mathrm{R}^{2}$ is always greater than that of C-CAPM and the absolute intercepts of three-factor are smaller than that of C-CAPM after June 2018.

We also focus on the top 300 cryptocurrencies with the highest liquidity using the same breakpoints in Section 2 and report the results in Table 6, where three-factor model increases average absolute intercept and $\mathrm{R}^{2}$. The average standard error also declines from

\footnotetext{
8 We only report the matrices of the intercepts and their t-statistics to conserve space, the full results are results are available on request.

9 https://coinmarketcap.com/charts/\#dominance-percentage.
} 
0.0140 to 0.0136 . Consequently, three-factor model still denominates C-CAPM model. Therefore, we show that the model's performance is not sensitive to the factors definition.

\section{Conclusion}

This paper sheds light on cryptocurrency pricing by incorporating size and reversal factors. We find that small cryptocurrencies tend to have higher average returns and the losers always perform better than winners. Specifically, the reversal returns also increase from bigger to smaller cryptocurrencies. The three-factor model strongly denominates the CCAPM that only includes excess market return. After re-constructing factors and concentrating on a smaller sample, we find the three-factor model still performs well. Therefore we show that the size and reversal factors can explain cryptocurrency returns better than the traditional CAPM model. 


\section{Reference}

Banz, R. W. 1981. The relationship between return and market value of common stocks. Journal of Financial Economics, 9(1), 3-18.

Carhart, M. M. 1997. On persistence in mutual fund performance. The Journal of Finance, 52(1), 57-82.

Corbet, S., Cumming, D. J., Lucey, B. M., Peat, M., \& Vigne, S. 2019. Investigating the Dynamics Between Price Volatility, Price Discovery, and Criminality in Cryptocurrency Markets. Available at SSRN: https:/ /ssrn.com/abstract $=3384707$.

Demir, E., Gozgor, G., Lau, C. K. M., \& Vigne, S. 2018. Does Economic Policy Uncertainty Predict the Bitcoin Returns? An Empirical Investigation. Finance Research Letters, 26, 145-149.

Fama, E. F., \& French, K. R. 1993. Common risk factors in the returns on stocks and bonds. Journal of Financial Economics, 33(1), 3-56.

Fama, E. F., \& French, K. R. 2012. Size, value, and momentum in international stock returns. Journal of Financial Economics, 105(3), 457-472.

Fama, E. F., \& French, K. R. 2015. A five-factor asset pricing model. Journal of Financial Economics, 116(1), 1-22.

Grobys, K., \& Sapkota, N. 2019. Cryptocurrencies and momentum. Economics Letters, 180, 6-10.

Jegadeesh, N., \& Titman, S. 1993. Returns to buying winners and selling losers: Implications for stock market efficiency. The Journal of Finance, 48(1), 65-91.

Nadarajah, S., \& Chu, J. 2017. On the inefficiency of Bitcoin. Economics Letters, 150, 6-9.

Platanakis, E., Sutcliffe, C., \& Urquhart, A. 2018. Optimal vs naïve diversification in cryptocurrencies. Economics Letters, 171, 93-96.

Platanakis, E., \& Urquhart, A. 2019. Should Investors Include Bitcoin in Their Portfolios? A Portfolio Theory Approach. Available at SSRN: https://ssrn.com/abstract $=3215321$.

Shen, D., Urquhart, A., \& Wang, P. 2019. Does twitter predict Bitcoin? Economics Letters, 174, 118-122.

Tiwari, A. K., Jana, R. K., Das, D., \& Roubaud, D. 2018. Informational efficiency of Bitcoin-An extension. Economics Letters, 163, 106-109.

Urquhart, A. 2016. The inefficiency of Bitcoin. Economics Letters, 148, 80-82.

Urquhart, A. 2018. What causes the attention of Bitcoin? Economics Letters, 166, 40-44.

Wei, W. C. (2018). Liquidity and market efficiency in cryptocurrencies. Economics Letters, 168, 21-24. 

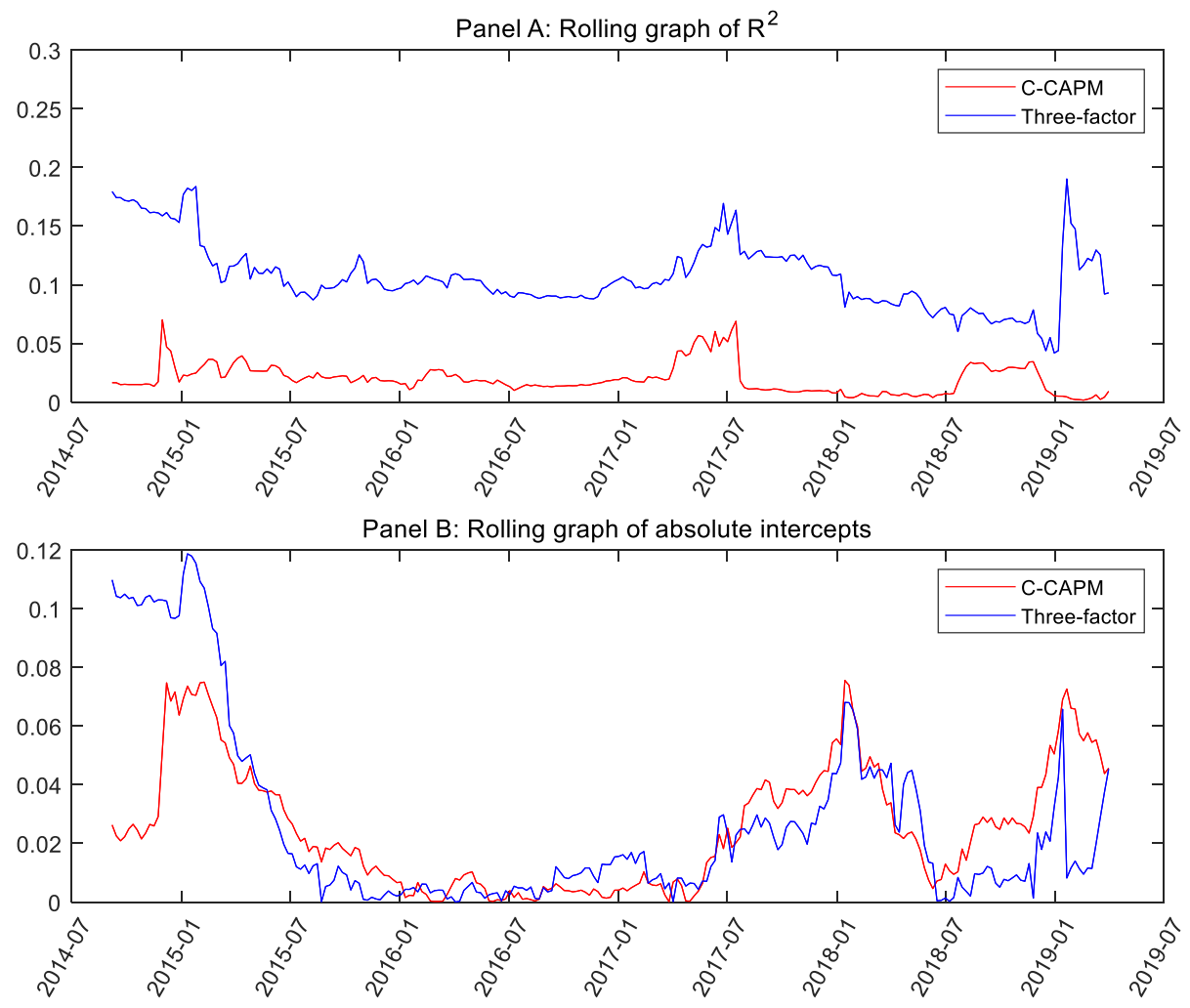

Figure 1. Rolling plot of $\mathrm{R}^{2}$ and absolute intercepts 
Table 1. Returns of $\mathrm{J}-\mathrm{K}$ portfolios

The portfolios are constructed based on J-week lagged returns and held for K weeks. An equal-weight portfolio of in the lowest past return decile is the sell portfolio and the highest return decile is the buy portfolio. The $\mathrm{t}$ statistics are reported in parentheses. Significance at the $1 \%, 5 \%$, or $10 \%$ level is denoted by ***, **, or *, respectively.

\begin{tabular}{|c|c|c|c|c|c|c|}
\hline & J & $\mathrm{K}=$ & 1 & 2 & 3 & 4 \\
\hline \multirow[t]{2}{*}{1} & Buy & & $-0.123^{* * *}$ & $-0.147 * * *$ & $-0.155^{* * *}$ & $-0.151 * * *$ \\
\hline & & & $(-8.751)$ & $(-8.083)$ & $(-7.074)$ & $(-4.937)$ \\
\hline \multirow[t]{2}{*}{1} & Sell & & $0.097 * * *$ & $0.098^{* * *}$ & $0.106^{* * *}$ & $0.087 * * *$ \\
\hline & & & $(7.297)$ & $(4.867)$ & (3.983) & $(2.915)$ \\
\hline \multirow[t]{2}{*}{1} & Buy-Sell & & $-0.220 * * *$ & $-0.245^{* * *}$ & $-0.261 * * *$ & $-0.238 * * *$ \\
\hline & & & $(-17.294)$ & $(-16.173)$ & $(-14.827)$ & $(-11.428)$ \\
\hline \multirow[t]{2}{*}{2} & Buy & & $-0.024^{* *}$ & $-0.032 *$ & -0.0270 & -0.0330 \\
\hline & & & $(-2.160)$ & $(-1.876)$ & $(-1.000)$ & $(-1.054)$ \\
\hline \multirow[t]{2}{*}{2} & Sell & & 0.0010 & 0.0130 & -0.0060 & -0.0040 \\
\hline & & & $(0.055)$ & $(0.593)$ & $(-0.237)$ & $(-0.109)$ \\
\hline \multirow[t]{2}{*}{2} & Buy-Sell & & $-0.025^{* *}$ & $-0.045^{* * *}$ & -0.0220 & -0.0300 \\
\hline & & & $(-2.358)$ & $(-2.648)$ & $(-1.072)$ & $(-1.423)$ \\
\hline \multirow[t]{2}{*}{3} & Buy & & -0.0070 & -0.0030 & -0.0100 & -0.0180 \\
\hline & & & $(-0.653)$ & $(-0.151)$ & $(-0.376)$ & $(-0.572)$ \\
\hline \multirow[t]{2}{*}{3} & Sell & & 0.0080 & -0.0100 & -0.0080 & -0.0090 \\
\hline & & & $(0.537)$ & $(-0.552)$ & $(-0.295)$ & $(-0.292)$ \\
\hline \multirow[t]{2}{*}{3} & Buy-Sell & & -0.0160 & 0.0070 & -0.0020 & -0.0080 \\
\hline & & & $(-1.356)$ & $(0.395)$ & $(-0.120)$ & $(-0.438)$ \\
\hline \multirow[t]{2}{*}{4} & Buy & & 0.0030 & -0.0030 & -0.0090 & -0.0220 \\
\hline & & & $(0.185)$ & $(-0.149)$ & $(-0.336)$ & $(-0.783)$ \\
\hline \multirow[t]{2}{*}{4} & Sell & & $-0.018^{*}$ & -0.0160 & -0.0180 & -0.0120 \\
\hline & & & $(-1.678)$ & $(-0.696)$ & $(-0.663)$ & $(-0.380)$ \\
\hline \multirow[t]{2}{*}{4} & Buy-Sell & & $0.021 *$ & 0.0120 & 0.0090 & -0.0100 \\
\hline & & & $(1.767)$ & $(0.830)$ & $(0.525)$ & $(-0.561)$ \\
\hline
\end{tabular}


Table 2. Summary statistics for 25 portfolios formed on size and reversal.

\begin{tabular}{|c|c|c|c|c|c|c|}
\hline \multirow{2}{*}{$\begin{array}{l}\text { Size } \\
\text { quintiles }\end{array}$} & \multicolumn{6}{|c|}{ Prior returns quintiles } \\
\hline & UP & 2 & 3 & 4 & Down & Down-Up \\
\hline Big & -0.039 & -0.008 & -0.001 & -0.011 & 0.003 & $0.041(3.918)^{* * *}$ \\
\hline 2 & -0.063 & -0.007 & -0.003 & -0.008 & -0.005 & $0.050(4.167)^{* * *}$ \\
\hline 3 & -0.098 & -0.010 & -0.004 & -0.001 & 0.024 & $0.113(8.715)^{* * *}$ \\
\hline 4 & -0.103 & -0.012 & 0.014 & 0.015 & 0.035 & $0.123(7.614)^{* * *}$ \\
\hline Small & -0.121 & 0.015 & 0.015 & 0.048 & 0.179 & $0.283(15.189)^{* * *}$ \\
\hline Small-Big & $-0.076(-4.633)^{* * *}$ & $0.023(1.137)$ & $0.017(1.306)$ & $0.059(3.523)^{* * *}$ & $0.175(8.873)^{* * *}$ & \\
\hline
\end{tabular}

Significance at the $1 \%$ level is denoted by $* * *$.

Table 3. Descriptive statistics for three factors.

\begin{tabular}{llllllll}
\hline & \multicolumn{3}{c}{ Summary statistics } & \multicolumn{3}{c}{ Correlation } \\
\hline & Mean & Std. & Skweness & Kurtosis & RMRF & SMB & DMU \\
\hline RMRF & 0.027 & 0.122 & 0.782 & 5.404 & 1.000 & & \\
SMB & 0.063 & 0.155 & 2.535 & 23.011 & 0.015 & 1.000 & \\
DMU & 0.160 & 0.160 & 0.123 & 4.509 & 0.024 & -0.040 & 1.000 \\
\hline
\end{tabular}

Table 4. Summary for C-CAPM and our three-factor regressions to explain weekly excess returns on portfolios from $5 \times 5$ sorts on size and reversal.

\begin{tabular}{|c|c|c|c|c|c|c|c|c|c|c|}
\hline \multicolumn{11}{|c|}{ Panel A: Intercepts from C-CAPM and three-factor regressions } \\
\hline & \multicolumn{5}{|c|}{ a } & \multicolumn{5}{|c|}{$\mathrm{t}(\mathrm{a})$} \\
\hline & $\mathrm{Up}$ & 2 & 3 & 4 & Down & Up & 2 & 3 & 4 & Down \\
\hline \multicolumn{11}{|l|}{ C-CAPM } \\
\hline Big & -0.043 & -0.014 & -0.008 & -0.017 & -0.003 & -3.607 & -1.077 & -0.830 & -1.438 & -0.265 \\
\hline 2 & -0.065 & -0.010 & -0.009 & -0.012 & -0.009 & -4.857 & -0.879 & -0.771 & -1.075 & -0.688 \\
\hline 3 & -0.102 & -0.015 & -0.013 & -0.004 & 0.021 & -7.065 & -0.939 & -0.814 & -0.267 & 1.651 \\
\hline 4 & -0.101 & -0.016 & 0.014 & 0.007 & 0.029 & -5.889 & -1.133 & 0.907 & 0.473 & 1.991 \\
\hline Small & -0.122 & 0.020 & 0.013 & 0.044 & 0.178 & -6.925 & 0.723 & 0.733 & 2.180 & 7.999 \\
\hline \multicolumn{11}{|c|}{ Three-factor } \\
\hline Big & -0.031 & -0.009 & -0.003 & -0.039 & -0.012 & -2.007 & -0.664 & -0.409 & -2.737 & -0.848 \\
\hline 2 & -0.048 & -0.015 & -0.009 & -0.027 & -0.038 & -2.517 & -0.992 & -0.795 & -1.933 & -2.419 \\
\hline 3 & -0.076 & -0.040 & -0.020 & -0.007 & -0.014 & -3.880 & -2.348 & -1.298 & -0.827 & -0.933 \\
\hline 4 & -0.097 & -0.012 & 0.000 & -0.025 & -0.012 & -4.178 & -0.813 & -0.809 & -1.687 & -0.721 \\
\hline Small & -0.082 & -0.010 & -0.024 & -0.009 & -0.007 & -4.436 & -0.525 & -1.363 & -0.597 & -0.575 \\
\hline \multicolumn{11}{|c|}{ Panel B: Summary statistics for regressions. } \\
\hline & $|\mathrm{a}|$ & $\mathrm{R}^{2}$ & $\mathrm{~s}(\mathrm{a})$ & & & & $|\mathrm{a}|$ & $\mathrm{R}^{2}$ & $\mathrm{~s}(\mathrm{a})$ & \\
\hline C-CAPM & 0.0356 & 0.0052 & 0.0149 & & & Three-factor & 0.0266 & 0.0695 & 0.0146 & \\
\hline
\end{tabular}


Table 5. Summary for our three-factor regressions using alternative factor definition.

\begin{tabular}{|c|c|c|c|c|c|c|c|c|c|c|}
\hline \multicolumn{11}{|c|}{ Panel A: Intercepts from three-factor regressions } \\
\hline & \multicolumn{5}{|c|}{$\mathrm{a}$} & \multicolumn{5}{|c|}{$t(a)$} \\
\hline & $\mathrm{Up}$ & 2 & 3 & 4 & Down & Up & 2 & 3 & 4 & Down \\
\hline Big & -0.012 & 0.007 & -0.005 & -0.018 & -0.019 & -1.376 & 0.513 & -0.442 & -1.507 & -1.613 \\
\hline 2 & -0.041 & -0.009 & 0.004 & -0.014 & -0.014 & -2.946 & -0.747 & 0.380 & -1.254 & -1.072 \\
\hline 3 & -0.071 & -0.004 & -0.011 & -0.014 & 0.023 & -5.233 & -0.240 & -0.741 & -1.051 & 1.843 \\
\hline 4 & -0.050 & -0.011 & 0.022 & 0.006 & 0.017 & -3.678 & -0.763 & 1.517 & 0.447 & 1.182 \\
\hline Small & -0.072 & 0.041 & 0.015 & 0.038 & 0.180 & -4.538 & 2.787 & 0.993 & 1.868 & 9.039 \\
\hline \multicolumn{11}{|c|}{ Panel B: Summary statistics for regressions. } \\
\hline & $|\mathrm{a}|$ & $\mathrm{R}^{2}$ & $\mathrm{~s}(\mathrm{a})$ & & & & & & & \\
\hline Three-factor & 0.0288 & 0.1569 & 0.0138 & & & & & & & \\
\hline
\end{tabular}

Table 6. Summary for C-CAPM and three-factor regressions using top 300 cryptocurrencies.

\begin{tabular}{|c|c|c|c|c|c|c|c|c|c|c|}
\hline \multicolumn{11}{|c|}{ Panel A: Intercepts from C-CAPM and three-factor regressions } \\
\hline & \multicolumn{5}{|c|}{ a } & \multicolumn{5}{|c|}{$\mathrm{t}(\mathrm{a})$} \\
\hline & Up & 2 & 3 & 4 & Down & $\mathrm{Up}$ & 2 & 3 & 4 & Down \\
\hline \multicolumn{11}{|l|}{ C-CAPM } \\
\hline Big & 0.012 & 0.003 & -0.004 & -0.014 & -0.011 & 0.745 & 0.247 & -0.484 & -1.537 & -1.169 \\
\hline 2 & 0.002 & 0.003 & 0.008 & -0.001 & -0.003 & 0.182 & 0.258 & 0.684 & -0.117 & -0.234 \\
\hline 3 & -0.026 & -0.005 & 0.002 & -0.005 & -0.002 & -1.670 & -0.328 & 0.126 & -0.362 & -0.143 \\
\hline 4 & 0.011 & 0.013 & 0.022 & -0.013 & 0.041 & 0.520 & 0.827 & 1.365 & -0.970 & 2.761 \\
\hline Small & 0.009 & 0.020 & 0.029 & 0.025 & 0.053 & 0.421 & 1.152 & 1.769 & 1.650 & 2.891 \\
\hline \multicolumn{11}{|c|}{ Three-factor } \\
\hline Big & 0.005 & 0.022 & 0.007 & -0.007 & -0.008 & 0.279 & 1.727 & 0.657 & -0.622 & -0.693 \\
\hline 2 & -0.001 & 0.012 & 0.008 & 0.012 & -0.009 & -0.145 & 0.864 & 0.579 & 0.924 & -0.673 \\
\hline 3 & -0.001 & 0.005 & 0.013 & 0.014 & 0.003 & -0.135 & 0.397 & 0.862 & 0.979 & 0.304 \\
\hline 4 & 0.020 & 0.016 & 0.014 & 0.003 & 0.018 & 0.887 & 0.871 & 0.934 & 0.295 & 1.325 \\
\hline Small & 0.015 & 0.014 & 0.022 & 0.019 & 0.019 & 0.846 & 0.787 & 1.366 & 1.245 & 1.338 \\
\hline \multicolumn{11}{|c|}{ Panel B: Summary statistics for regressions. } \\
\hline & $|\mathrm{a}|$ & $\mathrm{R}^{2}$ & $\mathrm{~s}(\mathrm{a})$ & & & & $|\mathrm{a}|$ & $\mathrm{R}^{2}$ & $\mathrm{~s}(\mathrm{a})$ & \\
\hline C-CAPM & 0.0134 & 0.0047 & 0.0140 & & & Three-factor & 0.0115 & 0.0555 & 0.0136 & \\
\hline
\end{tabular}

